\title{
Distribusi Material Padatan Tersuspensi di Perairan Semarang dengan Penginderaan Jauh
}

\author{
Adzkia Pincta Milenia*, Anindya Wirasatriya, Lilik Maslukah, Muh. Yusuf, Muhammad Helmi
}

\author{
Departemen Oseanografi, Fakultas Perikanan dan Ilmu Kelautan, Universitas Diponegoro \\ Jl.Prof.H.Soedarto,S.H,Tembalang Semarang.50275Telp/fax(024)7474698 \\ Email: *adzkiapincta@gmail.com
}

\begin{abstract}
Abstrak
Muara sungai Banjir Kanal Barat sebagai tempat strategis yang sangat berpotensi menerima limbah baik limbah kegiatan rumah tangga/pemukiman maupun limbah dari kegiataan industri. Limbah tersebut menyebabkan perairan sekitar menjadi keruh yang berkaitan peningkatan sedimen tersuspensi di daerah tersebut. Pendekatan dengan citra penginderaan jauh merupakan alternatif untuk mengetahui sebaran material padatan tersuspensi (MPT). Tujuan penelitian ini adalah menganalisis nilai sebaran MPT di muara Banjir Kanal Barat Semarang. Penelitian ini dilakukan pada tanggal 11 Agustus 2020 di muara Sungai Banjir Kanal Barat, Kota Semarang. Pengambilan sampel MPT di lapangan dilakukan pada 100 stasiun pada kedalaman 1 meter. Data MPT dan Reflectance Remote Sensing (RRS) diperoleh dari situs sentinel copernicus rekaman pada tanggal 11 Agustus 2020, merupakan data citra satelit Sentinel-2 dengan resolusi $10 \mathrm{~m}$. Data citra satelit Sentinel-2 diolah dengan pendekatan algoritma Syarif Budhiman (2004). Hasil penelitian menunjukkan bahwa konsentrasi MPT hasil observasi lapangan diperoleh rentang nilai antara 32,72 - 75,46 mg/L, sedangkan berdasarkan analisis MPT dengan citra satelit sebesar 22,51 - 35,48 mg/L. Nilai akurasi bias parameter MPT sebesar 20,43. Nilai RMSE parameter MPT sebesar 21,53.
\end{abstract}

Kata kunci : Muatan Padatan Tersuspensi, Sentinel-2, Semarang

\begin{abstract}
The estuary of the West Flood Canal is a strategic place that has the potential to receive waste, both household/residential activity waste and industrial waste. The waste causes the surrounding waters to become cloudy due to the increase in suspended sediment in the area. The approach with remote sensing imagery is an alternative to determine the distribution of suspended solids (MPT). The purpose of this study was to analyze the value of the distribution of MPT at the estuary of the West Flood Canal in Semarang. This research was conducted on August 11, 2020 at the mouth of the West Flood Canal, Semarang City. MPT sampling in the field was carried out at 100 stations at a depth of 1 meter. MPT and Reflectance Remote Sensing (RRS) data obtained from the sentinel site Copernicus recording on August 11, 2020, is data from the Sentinel-2 satellite image with a resolution of $10 \mathrm{~m}$. Sentinel-2 satellite image data was processed using the Syarif Budhiman algorithm approach (2004). The results showed that the MPT concentration obtained from field observations ranged from $32.72-75.46 \mathrm{mg} / \mathrm{L}$, while based on MPT analysis with satellite imagery, it was $22.51-35.48 \mathrm{mg} / \mathrm{L}$. The value of the MPT parameter bias accuracy is 20.43. The RMSE value of the MPT parameter is 21.53 .
\end{abstract}

Keywords : Total Suspended Solids, Sentinel-2, Semarang

\section{PENDAHULUAN}

Wilayah pesisir merupakan tempat pertemuan antara daratan dan lautan, sering didefinisikan sebagi daerah interface atau daerah transisi dimana segala macam proses daratan dan lautan terjadi (Dahuri et al., 1996). Kawasan pesisir memiliki potensi sumberdaya yang besar, sehingga dapat dimanfaatkan untuk berbagai kegiatan perekonomian seperti penangkapan dan budidaya perikanan, industri dan pariwisata. Selain itu, wilayah pesisir juga merupakan daerah yang rentan terjadi pencemaran, juga digunakan sebagai tempat pembuangan limbah. Salah satunya terjadi di perairan Muara sungai Banjir Kanal Barat Kota Semarang. 
Muara sebagai penghubung antara sungai dan laut, tidak luput dari terjadinya sedimentasi karena sedimen dari hilir dan sedimen dari laut akan bertemu di daerah tersebut (Setiawan et al., 2012). Banjir Kanal Barat (BKB) merupakan penyatuan dari tiga sungai besar yaitu Sungai Kreo, Kripik, dan Garang. Di Kecamatan Gunungpati, ketiga sungai itu menyatu dan menjadi hulu dari BKB. Sungai Banjir Kanal Barat merupakan daerah perairan yang digunakan masyarakat sekitar sebagai tempat pembuangan limbah domestik, seperti limbah industri, limbah rumah tangga, dan limbah lainnya yang berasal dari sekitar daerah aliran sungai tersebut. Selain itu, fungsi lain dari sungai ini dijadikan warga sekitar sebagai tempat seperti budidaya perairan, reklamasi, dan pengelolaan lahan.

Wilayah Sungai BKB digunakan sebagai pemukiman warga dan tempat bedirinya berbagai industri yang limbahnya langsung menuju ke perairan. Salah satu limbah yang masuk atau di buangnya ke perairan yaitu limbah rumah tangga seperti detergen, buangan sisa makanan, maupun limbah lainnya yang menyebabkan banyaknya sumber pencemar yang masuk kedalam perairan (Purba et al., 2020). Menurut Siregar dan Alan (2016), limbah domestik dan perubahan penggunaan lahan yang meningkat sebesar $85 \%$ selama dua belas tahun terakhir terjadi di muara sungai BKB. Hasil dari aktivitas manusia tersebut menyebabkan perairan sekitar menjadi keruh, akibat peningkatan sedimen tersuspensi (MPT) di daerah tersebut. Perairan yang keruh dapat menghambat penetrasi cahaya matahari ke dalam perairan dan dapat mengganggu proses fotosintesis, dan berakibat terganggunya organisme perairan yang hidup di dalamnya.

Sentinel-2 merupakan satelit dari program European Space Agency (ESA) Copernicus dengan orbit polar yang diluncurkan pada tahun 2015. Sentinel-2 ini dapat digunakan untuk kepentingan pemantauan pertanian, hutan, perubahan penggunaan lahan, perubahan tutupan lahan, pemetaan variabel biofisik seperti kandungan klorofil daun, kadar air daun, indeks luas daun, pemantauan perairan pesisir dan pedalaman, serta risiko dan pemetaan bencana.

Penelitian ini dilakukan untuk mengetahui konsentrasi dan sebaran MPT di sekitar muara sungai Banjir Kanal Barat Kota Semarang dengan menggunakan kombinasi metode yaitu, observasi lapangan dan penginderaan jauh citra Sentinel-2 level 2A. Metode pengambilan data secara langsung di muara sungai Banjir Kanal Barat Kota Semarang sangat memperhatikan waktu pengambilan data dengan menyesuaikan saat citra satelit melewati daerah penelitian, agar didapatkan data yang akurat. Penelitian ini diharapkan dapat menjadi bahan rujukan dalam pengamatan kualitas perairan, khususnya untuk pengamatan MPT sebagai indikator kualitas perairan dan dapat dijadikan referensi dalam usaha penanganan masalah pada daerah tersebut.

Kota Semarang dan daerah sekitar muara sungai Banjir Kanal Barat termasuk pemukiman padat penduduk, sehingga aktifitas warga sekitar menjadi cukup tinggi. Menurut Tarigan et al. (2020), Proses penurunan konsentrasi padatan tersuspensi dari muara menuju laut mengindikasikan bahwa sumber berasal dari aliran sungai. Aktifitas warga berpengaruh terhadap kekeruhan yang berkaitan dengan peningkatan sedimen tersuspensi dan pendangkalan sungai Banjir Kanal Barat, dapat berakibat buruk bagi kehidupan manusia dan organisme hidup lainnya.

Sebaran material padatan tersuspensi (MPT) pernah dilakukan oleh beberapa peneliti sebelumnya oleh Febrianto dan Latifah (2017). Penelitian yang dilakukan sebelumnya ini, menggunakan data citra satelit Landsat 8. Penelitian MPT menggunakan data citra Sentinel-2 oleh Octaviana et al. (2020), menggunakan data dari citra satelit Sentinel-2A level-1C yang perlu dikembangkan menggunakan citra Sentinel-2A level-2A yang telah memiliki nilai Bottom of Atmospheric. Penelitian dengan citra satelit Sentinel-2A level-2A untuk mengetahui sebaran MPT telah dilakukan oleh Prasetiyo et al. (2019), penelitian tersebut menggunakan algoritma referensi dari citra satelit Landsat 8. Menurut Prasetiyo et al. (2019), hasil perhitungan MPT dengan algoritma Syarif Budhiman (2004) citra satelit Landsat 8 memiliki nilai akurasi yang bagus dibanding algoritma referensi lainnya yang dikaji.

\section{MATERI DAN METODE}

Penelitian dilaksanakan pada musim Timur 11 Agustus 2020 di Perairan Muara Sungai Banjir Kanal Barat Kota Semarang. Data sedimen tersuspensi dilakukan dengan cara pengambilan sampel di lapangan sebanyak 100 stasiun dengan kedalaman air kurang dari 1 meter saat kondisi surut. Pengambilan data MPT dengan basis penginderaan jauh diambil dari data citra yakni satelit sentinel-2 
Level 2A yang dapat diunduh dari website http://marine.copernicus.eu/. Data perekaman citra Sentinel2 Level 2A dilakukan pada saat pengambilan sampel di lapangan 11 Agustus 2020 pukul 09:30 WIB. Metode penelitian ini menggunakan metode kuantitatif dan metode eksploratif. Konsentrasi material padatan tersuspensi dapat diketahui dengan menggunakan metode gravimetri.

Pada penelitian ini menggunakan citra satelit Sentinel-2 level 2A, dan tahap koreksi geometrik tidak dilakukan. Koreksi radiometrik tidak dilakukan pada citra satelit Sentinel-2 level 2A, karena produk level 2A sudah terkoreksi radiometrik dan memiliki nilai reflektansi Bottom of Atmosphere (Gatti dan Bertolini, 2015). Pada penelitian ini untuk memberikan nilai nol untuk objek yang bukan berupa laut perlu adanya pemisahan objek (Masking). Masking citra antara perairan dan daratan bertujuan agar nilai spektral yang digunakan dalam proses interpretasi tidak dipengaruhi oleh nilai spektral dari daratan. Masking 21 dilakukan dengan menggunakan kanal Near Infrared (NIR).

Proses pengolahan citra satelit pengindraan jauh untuk memberikan tampilan yang lebih informatif pada citra perlu dilakukan penajaman citra. Penajaman citra dilakukan dengan mentransformasikan nilai spektral menjadi konsentrasi material padatan tersuspensi menggunakan formula yang diturunkan dari algoritma empiris. Algoritma yang digunakan dalam penelitian ini yakni algoitma Syarif Budhiman (Novitasari et al., 2020) :

Keterangan:

$$
\mathrm{SS}(\mathrm{mg} / \mathrm{l})=8,1429 \times \exp ^{\wedge}((23,704 \times \operatorname{Rrs}(\lambda 4))
$$

TSS : Material padatan tersuspensi

$\operatorname{Rrs}(\lambda 4)$ : Nilai reflektan kanal merah

Uji akurasi hasil pendugaan algoritma Syarif Budhiman (2004), untuk mengetahui seberapa besar kemiripan antara data yang diperoleh melalui pemodelan dengan data yang sebenarnya. Nilai akurasi data dapat diketahui dengan menghitung seberapa besar error (kesalahan) pada data yang didapat. Menurut Nugroho (2013), nilai kesalahan dapat dihitung dengan rumus Bias dan Root Mean Square Error (RMSE), sebagai berikut :

$$
\begin{gathered}
R M S E=\sqrt{\frac{1}{n} \Sigma(X m-X e)^{2}} \\
\text { Bias }=(X e-X m)
\end{gathered}
$$

Keterangan:

$\mathrm{Xe}=$ Nilai hasil pengukuran lapangan yang dianggap benar

$\mathrm{Xm}=$ Nilai hasil pengolahan

$\mathrm{n}=$ Jumla data

Nilai akurasi data dapat diketahui dengan menghitung seberapa besar nilai kesalahan relatif pada data yang didapat. Semakin kecil mendekati nol nilai Bias dan RMSE, maka semakin baik data tersebut. Nilai kesalahan dapat dihitung dengan rumus Bias dan RMSE. 


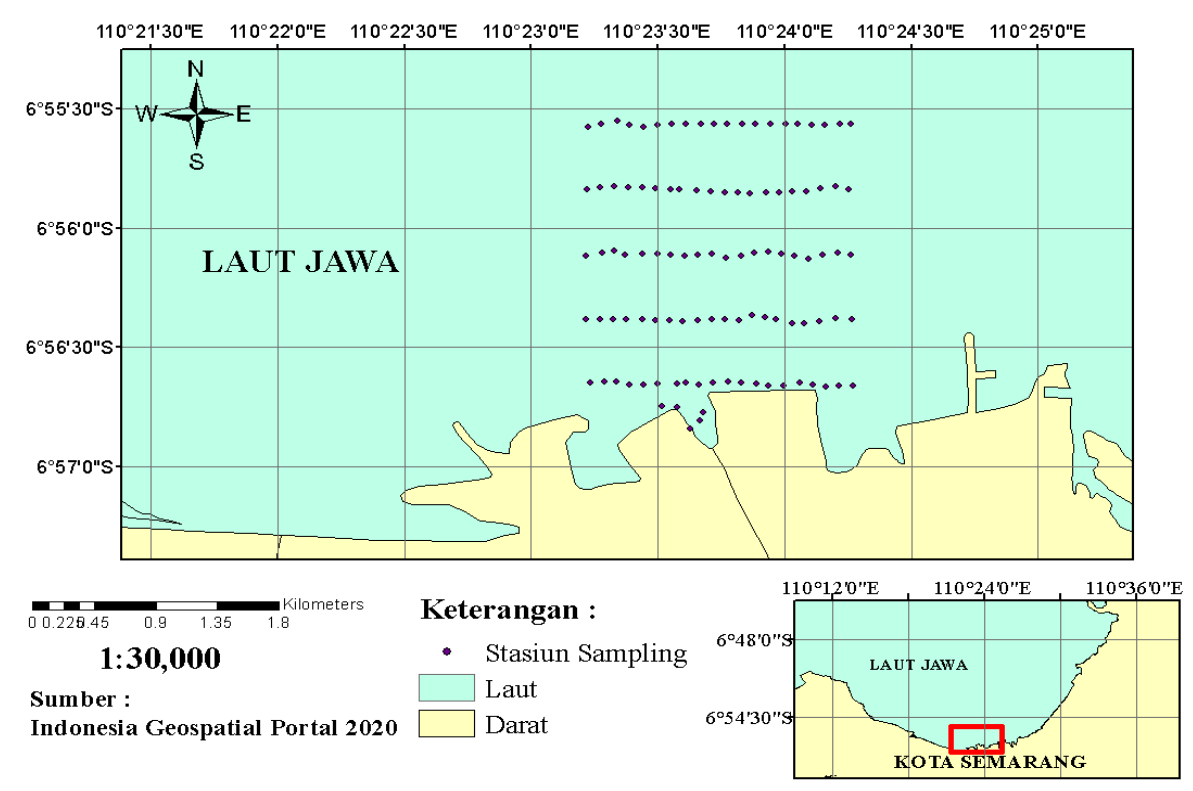

Gambar 1. Peta Lokasi Penelitian

\section{HASIL DAN PEMBAHASAN}

Nilai Material Padatan Tersuspensi Hasil Observasi Lapangan

Nilai konsentrasi Material Padatan Tersuspensi (MPT) di Muara Banjir Kanal Barat Kota Semarang dari hasil observasi lapangan didapat rentang nilai antara $32,72-75,46 \mathrm{mg} / \mathrm{l}$ pada bulan Agustus 2020.

Tabel 1. Nilai Konsentrasi MPT Hasil Observasi Lapangan

\begin{tabular}{cc}
\hline Kategori & Nilai MPT $(\mathrm{mg} / \mathrm{l})$ \\
\hline Tertinggi & 75,46 \\
Terendah & 32,72 \\
Rata-rata & 43,03 \\
\hline
\end{tabular}

\section{Sebaran Material Padatan Tersuspensi Citra Sentinel-2 dengan Algoritma Syarif Budhiman (2004)}

Citra sateilit Sentinel-2 masih sering dipengaruhi awan ataupun kabut (haze) yang terekam pada citra, sehingga pemilihan Sentinel-2 Level 2A adalah pilihan yang dirasa tepat. Hal ini dikarenakan pola spektral citra koreksi atmosfer Level-2A Bottom of Atmosphere (BOA) lebih baik dari pada pola spektral koreksi Sentinel-2 Level-1C Top of Atmosphere (TOA) dan tidak mengubah karakteristik pola spektral dari setiap jenis obyek. Prosesor koreksi atmosfer menggunakan perangkat lunak Sen2Cor yang dikembangkan untuk mengoreksi data tunggal Sentinel-2 Level-1C TOA dari efek atmosfer untuk menghasilkan Level-2A BOA (Ulfa et al.,2019).

Hasil dari pendugaan citra satelit Sentinel-2 Level 2A dari setiap stasiun diperoleh nilai rata-rata MPT algoritma Syarif Budhiman (2004) berada pada rentang 22,94 mg/l stasiun 87 hingga 33,52 mg/l pada stasiun 103 dengan nilai rata-rata $27,7 \mathrm{mg} / \mathrm{l}$. 

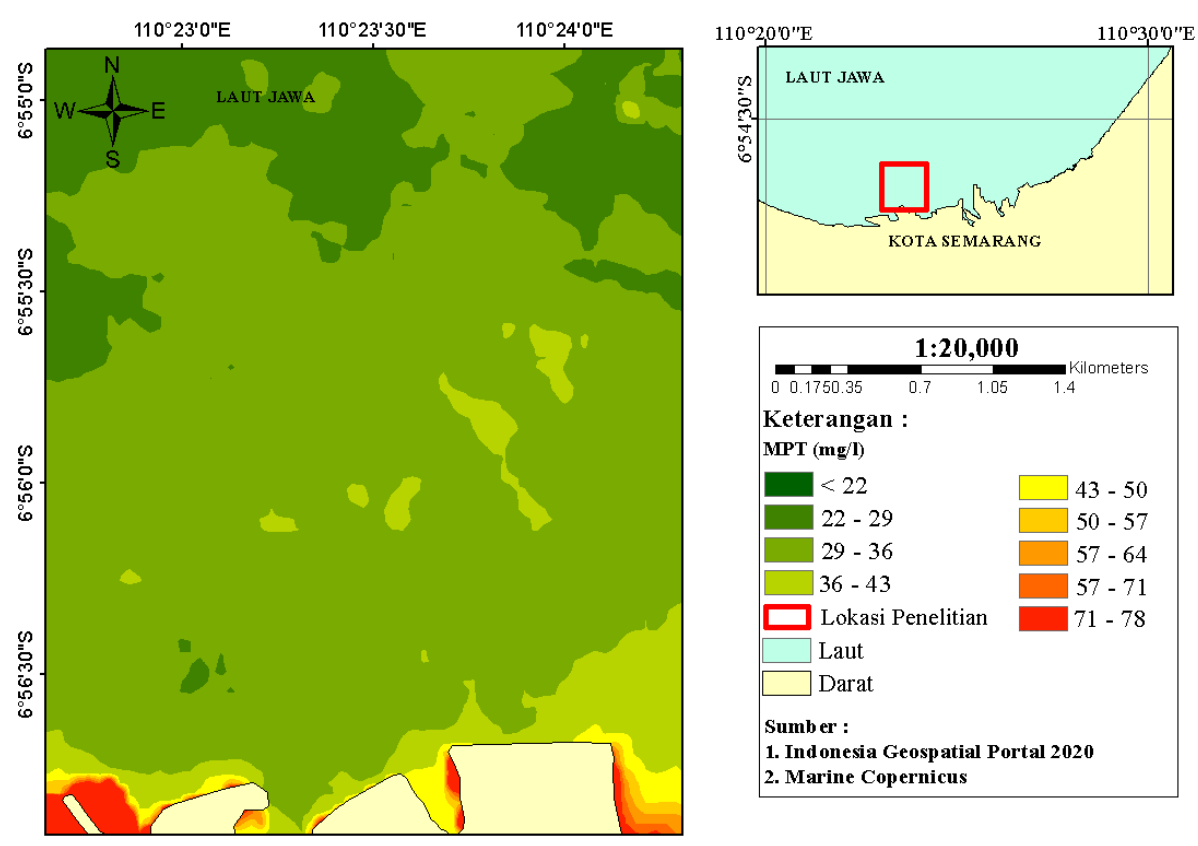

Gambar 2. Peta Sebaran MPT Algoritma Syarif Budhiman (2004)

Pola sebaran MPT disajikan pada gambar 2. Pada gambar tersebut memiliki dominasi warna yang berbeda. Algoritma Syarif Budhiman (2004) memiliki dominasi warna merah pada daerah dekat muara dan warna hijau muda pada daerah menuju laut lepas atau daerah jauh dari muara. Berdasar hasil yang diperoleh algoritma Syarif Budhiman (2004) memiliki rentang nilai konsentrasi MPT yang berbeda menyesuaikan warna sebarannya. Hasil rata-rata uji validasi pendugaan algoritma Syarif Budhiman (2004) berupa nilai bias dan RMSE sebesar -20,43 dan 21,53. Wirasatriya et al. (2009) menyatakan bahwa, validasi data berdasarkan nilai bias dan RMSE yang mendekati nol merupakan hasil yang memiliki tingkat akurasi tinggi, sehingga dapat disimpulkan bahwa penggunaan algoritma Syarif Budhiman (2004) kurang sesuai untuk menduga konsentrasi di wilayah kajian.

Pola sebaran MPT, hasil perekaman citra satelit Sentinel-2 Level 2A dengan pendugaan algoritma Syarif Budhiman (2004) dan hasil observasi lapangan memiliki konsentrasi tinggi pada daerah dekat muara sungai dan akan semakin berkurang ketika menjauh dari daerah muara sungai atau menuju laut lepas. Hal ini dikarenakan muara sungai merupakan daerah yang dekat dengan daratan serta merupakan buangan dari air sungai ke laut, dimana daratan dan air sungai merupakan penyuplai MPT. Menurut Prasetyo et al. (2019), bahwa muara sungai merupakan perantara terbawanya MPT dari sungai ke laut lepas yang ditunjukkan dengan tingginya konsentrasi MPT dimuara sungai. Perekaman citra satelit Sentinel-2A yang dilakukan pada pukul 02:35 UTC atau 9:30 WIB merupakan kondisi surut menuju pasang yang dapat menyebabkan daerah dekat muara sungai memiliki nilai konsentrasi MPT yang lebih besar dibanding dengan daerah yang jauh dari muara sungai atau menuju laut lepas. Diperkuat dengan pendapat Lanuru dan Ferayanti (2011), bahwa ketika kondisi surut menuju pasang, muka air laut akan lebih tinggi dibanding daerah badan dan mulut sungai/muara, sehingga pengadukan dan pelepasan MPT lebih banyak terjadi di muara sungai. Selain itu, kecepatan arus mempengaruhi distribusi MPT yang akan menyebabkan perbedaan sebaran MPT pada tiap daerah yang diteliti (Yusuf et al., 2021).

\section{KESIMPULAN}

Hasil uji laboratorium dari hasil observasi lapangan memiliki konsentrasi MPT sebesar 32,72 $\mathrm{mg} / \mathrm{l}$ hingga 75,46 mg/l. Nilai konsentrasi MPT dari pendugaan algoritma Syarif Budhiman (2004) sebesar 22,51 mg/l hingga 35,48 mg/l. Hasil dari penerapan pendugan algoritma Syarif Budhiman (2004) memiliki akurasi yang kurang bagus, ditinjau dari nilai bias dan RMSE sebesar -20,43 dan 21,53. 
Hal ini dapat disimpulkan, algoritma Syarif Budhiman (2004) kurang sesuai diterapkan pada pendugaan MPT di perairan Muara Sungai Banjir Kanal Barat, Kota Semarang.

\section{DAFTAR PUSTAKA}

Chester, R. 1990. Marine Geochemistry. Unwin Hyman Ltd, London.

Dahuri, R., J. Rais, M.J. Sitepu dan S.P. Ginting. 1996. Pengelolaan Sumberdaya Wilayah Pesisir dan Lautan Secara Terpadu. PT. Pradnya Paramita, Jakarta.

Djokosetiyanto dan B. Hardjojo. 2005. Pengukuran dan Analisis Kualitas Air. Universitas Terbuka, Jakarta

Febrianto, S. dan N. Latifah. 2017. Pemetaan Pola Sebaran Total Suspended Solid (TSS) di Perairan Teluk Semarang menggunakan Citra Satelit Landsat 7 ETM dan Landsat 8. Jurnal Harpodon Borneo, 10(1): 56-60.

Gatti, A., dan A. Bertolini. 2015. Sentinel-2 Products Specification Document. Diakses pada 02 Desember 2020, dari https://sentinel.esa.int/documents/247904/685211/Sentinel-2-ProductSpecifications-Document(2 Desember 2020)

Lanuru, M., dan D. Ferayanti. 2011. Hubungan Sedimen Dasar Perairan dengan Penyebaran Lamun (Seagrass) di Teluk Pare-pare, Sulawesi Selatan. Jurnal Omni-Akuatika, 10(13): 79-83.

Novitasari, A. Sukmono dan N. Bashit. 2020. Analisa Pengaruh Koreksi Atmosfer terhadap Akurasi Estimasi Kandungan TSS (Total Suspended Solid) menggunakan Citra Landsat 8. Jurnal Geodesi Undip, 9(1): 335-343.

Nugroho, A.K. 2013. Aplikasi SIG untuk Evaluasi Sistem Jaringan Drainase SUB DAS Gajahwong Kabupaten Bantul. Seminar Nasional Informatika, hlm. 64-69.

Octaviana, A., Y. Prasetyo dan F.J. Amarrohman. 2020. Analisis Perubahan Nilai Total Suspended Solid Tahun 2016 dan 2019 menggunakan Citra Sentinel 2A. Jurnal Geodesi Undip, 9(2): 167-176.

Prasetiyo, B.A., B. Rochaddi dan A. Satriadi. 2019. Aplikasi Citra Sentinel-2 untuk Pemetaan SebaranMaterial Padatan Tersuspensi Di Muara Sungai Wulan Demak. Journal of Marine Research, 8(4): 379-386.

Purba, R.D., Haeruddin, dan S. Rudiyanti. 2020. Analisis Beban Pencemaran Sungai Banjir Kanal Barat dan Sungai Silandak, Semarang. Journal of Maquares, 9(1): 67-71.

Satriadi, A. dan S. Widada. 2004. Distribusi Muatan Padatan Tersuspensi di Muara Sungai Bodri, Kabupaten Kendal. Imu Kelautan, 19(2): 01 - 107.

Sari, D. A., Haeruddin dan S. Rudiyanti. 2016. Analisis Beban Pencemaran Deterjen dan Indeks Kualitas Air di Sungai Banjir Kanal Barat, Semarang dan Hubungannya dengan Kelimpahan Fitoplankton. Jurnal Maquares. Universitas Diponegoro, 5(4): 353-364.

Setiawan, I., S. Purnawan dan Marwantim. 2012. Studi Sebaran Sedimen Berdasarkan Ukuran Butir di Perairan Kuala Gigieng, Kabupaten Aceh Besar, Provinsi Aceh. Jurnal Depik, 1(1): 31 - 36.

Siregara, V., dan A.F. Koropitan. 2016, Land use change and its impact to marine primary production in Semarang Waters. Procedia Environmental Sciences, 33: 520 - 531.

Tarigan, N.J., B. Rochaddi, P. Subardjo dan L. Maslukah. 2020. Sebaran Fosfor Anorganik Partikulat di Muara Sungai Banjir Kanal Barat Semarang. Journal of Marine Research, 9(4): 501-508.

Ulfa, K., Hendayani, F. Muchsin, D.S. Chandra, K.A. Pradono, L.Fibriawati, M.I. Oktavia dan K.W.V. Damanik. 2019. Analisa Pola Spektral Citra Sentinel-2 (Spectral Analysis Of Sentinel-2 Images). Berita Dirgantara. 20(2): 38-43.

Wirasatriya, A., H. Kawamura, dan F. Sakaida. 2009. SST Retrieval Using AVHRR on Board NOAA19 in the Seas Around Japan. Ilmu Kelautan., 14 (4): 227-233.

Yusuf, M., A. Pamungkas, M. Hudatwi, dan Irvani. 2021. Distribution of Turbidity Values, Total Suspended Solids and Heavy Metals $\mathrm{Pb}, \mathrm{Cu}$ in Tanah Merah Beach Waters and Semujur Island Waters, Bangka Tengah Regency. IOP Conf. Series: Earth and Environmental Science, 750 (012038): 1-9. 